\title{
Research on Integration of Warehouse Allocation in E-Commerce Enterprises
}

\author{
Hua Xuan, Lu Wang *, Liuyu Wen \\ School of Management Engineering, Zhengzhou University, Zhengzhou 450001, China
}

Keywords: E-commerce; Logistics; Warehouse Distribution Integration; Cost; Delivery Mode

\begin{abstract}
With the development of information technology and the Internet, e-commerce has become a fast developing emerging industry; especially the online shopping has become a household name. Logistics and electronic commerce are closely related to the two industries, the logistics service quality and efficiency of the development have a significant impact on the development of e-commerce. Distribution is the key to reflecting the level of logistics services. Firstly, the paper uses the center of gravity method to determine the location of the warehouse distribution center, and then through the mathematical calculation, compares the enterprise logistics cost and delivery time, making use of equilibrium analysis to discuss the business enterprise choose distribution model of influencing factors. Finally, through comparative analysis, it determines the impact of different distribution modes on the electricity supplier enterprises. After the analysis of different distribution modes of enterprise logistics, it has found out the optimum distribution model, which leads to the reduction of the cost of enterprise, and the rise of logistics service level. And it can be found that the warehouse distribution is the optimum choice. Through the study of warehouse distribution integration to achieve the mode of promotion and application, the paper wants to improve the competitiveness of enterprises and social economic benefits and social development level.
\end{abstract}

\section{INTRODUCTION}

Based on the rapid development of Internet technology, a new type of business transaction model e-commerce is emerging. With the rapid rise of e-commerce, a series of theoretical and practical changes have taken place in the circulation market. E-commerce breaks the boundaries of time and space, but also changes the capital flow, information flow and logistics of the overall operation process and environmental system. It can be said that e-commerce is a cross era business model, it divides the business and logistics, to speed up the whole social commodity circulation, improve the enterprise management to enhance the competitiveness of enterprises, optimize the logistics activities to reduce business costs.

At present, the development level of logistics cannot meet the needs of the development of e-commerce. Therefore, in order to develop e-commerce, we must pay attention to the development of offline logistics, so that logistics closely follow the pace of e-commerce development. Because the traditional electricity supplier mode has changed from $\mathrm{B} 2 \mathrm{~B}$ to $\mathrm{B} 2 \mathrm{C}$ mode, many e-commerce companies have no ability to warehousing and distribution. This makes the emergence of a lot of logistics services for the electricity supplier, in the field of warehousing and distribution, to provide low-cost, efficient logistics services, the distribution business to the upstream extension, to achieve integration of warehouse allocation.

As warehouse integration is a new concept, there are not many mature examples for reference and research. At present, many scholars and experts in the study of distribution mode, the main research direction is the traditional distribution mode, such as self-logistics, the third party logistics. Research methods are generally aimed at an industry or a certain enterprise, such as cold chain logistics, rural logistics, Tokyo logistics analysis, etc. There is little in-depth research on warehouse allocation integration, and the general research is not clear from the traditional model, and there is no specific case analysis. In this paper, in order to distinguish form positions with integration of specific research through the case analysis, the characteristics of the pattern, find out the reasons and advantages of this analysis of its development trend, discusses the factors influencing the distribution model of the enterprise, help business enterprise to find better distribution mode, reducing the cost and increase the quality of service the. So that the electricity supplier enterprises can better development, more able to meet customer needs.

\section{THE FORM OF WAREHOUSE AND DISTRIBUTION}

\subsection{Warehousing and distribution are responsible for the production enterprises}

This model refers to the establishment of a transportation department within the enterprise, and then is responsible for all the internal and external logistics activities required by the enterprise, especially the supply, sale and transportation of the products. This model is a logistics mode adopted by many domestic production enterprises, but this model has many disadvantages. The most prominent one is the waste of enterprise resources and the low efficiency of logistics.

\subsection{Warehousing and distribution by the electricity supplier responsible for enterprises}

The model refers to enterprises registered in the electronic business platform, to store their own goods in the electricity supplier's own warehouse, orders issued by the electronic platform of the distribution personnel for goods transportation and distribution. When choosing the appropriate transport equipment, the whole process of monitoring the goods transport process, while providing 
inventory information and sales forecast. At present, the warehouse allocation integration is in the name of this model. The model realizes the seamless docking of warehousing and distribution, making the whole logistics process more smooth and coordinated. Now most of the electricity supplier enterprises are small enterprises, their distribution capacity is limited, most rely on this new distribution mode, and help yourself to solve a series of problems after the order.

\subsection{Warehousing and distribution are responsible for the third party logistics enterprises}

This model refers to the electronic business enterprise put their products in the warehouse of the third party enterprises, when the customer orders, logistics enterprises to product loading, start distribution. The logistics undertaker of the mode is the third party logistics enterprise, which is an extension of the express delivery business to the upstream supply chain.

The above described a few cases, only the latter two ways is the true sense of Warehouse Integration model. Warehouse integration is to warehouse and distribution closely together, making the business process seamless docking, reducing a lot of unnecessary links. From the point of view of supply chain, logistics can only provide efficient and low cost services only when nodes are connected.

\section{CASE STUDY OF WAREHOUSE ALLOCATION INTEGRATION UNDER B2B BACKGROUND}

\subsection{Background}

Assume that the electricity supplier enterprise A enterprise is located in Guangzhou City, the main customer market concentrated in the central region, transportation locations are: Zhengzhou, Xi'an, Taiyuan, Wuhan, Hefei, Shijiazhuang. The company's monthly sales volume of $\mathrm{S}$ is one hundred thousand pieces, each weight average $5 \mathrm{~kg}$, covers an area of 0.2 square meters. Transport enterprises for freight, freight are 0.4 RMB / ton Y. The inventory cost C is $0.02 \mathrm{RMB} / \mathrm{m} 2$ / day, handling and handling fees and other expenses are 5000 RMB per month. Once the orders of less than 20 tons, $Y$ price is $0.4 \mathrm{RMB}$ / ton kilometer, not less than 20 tons, Y price is $0.3 \mathrm{RMB} /$ ton kilometer. Goods stored in warehouse allocation center, the cost of C is $0.03 \mathrm{RMB}$ / square meter / day, processing each order to add an additional $300 \mathrm{RMB}$. In the enterprise order at the beginning of the month, at the end of the inventory is 0 , the replenishment time is not considered. There are 6 orders per month, and the cost of transportation and distribution of local orders is ignored.

\subsection{Selection of warehouse distribution center}

\subsubsection{Calculation}

In order to select the best location of the warehouse in these 6 locations, the center of gravity method is usually used. First you build the model, then you collect the data from the model, and you get the results.
Assume that the existing $\mathrm{N}$ sites, select one point, so that starting from nowhere to reach the lowest total cost of other places. The coordinates of each point $\operatorname{are}\left(x_{i}, y_{i}\right)(i=1,2,3, \ldots \ldots, N)$, the distribution center to coordinate $(\mathrm{x}, \mathrm{y}) . \mathrm{h}_{\mathrm{i}}$ said from the distribution center to the destination I rates, $\mathrm{w}_{\mathrm{i}}$ said the demand to I, d_i said straight from the distribution center to the destination I, $\mathrm{C}$ on behalf of other expenses [17]. H represents the total cost from the distribution center to each destination, and the $\mathrm{F}(\mathrm{x})$ represents the total cost function, and the model can be established:

The objective function is: $\operatorname{Min} \mathrm{F}(\mathrm{x})$

Constraint condition is:

$$
\begin{aligned}
& \mathrm{H}=\sum_{\mathrm{i}=\mathbf{1}}^{\mathrm{N}} \mathbf{C}_{\mathbf{i}}=\sum_{\mathrm{i}=\mathbf{1}}^{\mathbf{N}} \mathbf{h}_{\mathbf{i}} \mathbf{w}_{\mathbf{i}} \mathbf{d}_{\mathbf{i}} ; \\
& \mathrm{F}(\mathrm{x})=\mathrm{H}+\mathrm{C}
\end{aligned}
$$

By calculation, the center position can be obtained:

$$
\mathrm{X}=\frac{\sum_{\mathrm{i}=\mathbf{1}}^{\mathrm{N}} \mathbf{h}_{\mathbf{i}} \mathbf{w}_{\mathrm{i}} \mathbf{x}_{\mathbf{i}} / \mathbf{d}_{\mathbf{i}}}{\sum_{\mathrm{i}=\mathbf{1}}^{\mathrm{N}} \mathbf{h}_{\mathbf{i}} \mathbf{w}_{\mathbf{i}} / \mathbf{d}_{\mathbf{i}}} \quad \mathrm{y}=\frac{\sum_{\mathrm{i}=\mathbf{1}}^{\mathrm{N}} \mathbf{h}_{\mathbf{i}} \mathbf{w}_{\mathbf{i}} \mathbf{y}_{\mathbf{i}} / \mathbf{d}_{\mathbf{i}}}{\sum_{\mathrm{i}=\mathbf{1}}^{\mathrm{N}} \mathbf{h}_{\mathbf{i}} \mathbf{w}_{\mathbf{i}} / \mathbf{d}_{\mathbf{i}}}
$$

According to the formula, the coordinates of the center position are calculated:

$X=3110039963 / 150=20733599.76$,

$\mathrm{Y}=1056460815 / 150=7043072.099$

The coordinates are converted to geographical latitude and longitude, the center of gravity is located at 113.84 degrees east longitude, 33.18 degrees north latitude, located on the map, belong to Henan Province, so Zhengzhou was selected as the site.

\subsubsection{Analysis of influencing factors}

Enterprises in the process of selection will be affected by the traffic volume and transportation distance of these two aspects.

First, because the freight is the same, according to the formula, it can be seen that the freight can be put forward from the formula, the upper and lower scores cancel each other, so the freight size has no influence on the enterprise location.

Then, when discussing the influence of the traffic volume, the distance is fixed, and the distance between the warehouse allocation center and each destination is the same. The higher the traffic volume is, the closer the site will be.

Finally, in the same discussion of the impact of distance, the volume of traffic must be fixed, and the demand for each site is the same. So the distance to the place, the final location will be closer to the place.

\subsection{Comparison of cost and response time of different modes}

\subsubsection{Collection of related data}

The calculation formula of inventory cost is: storage cost $=$ the beginning of the month inventory $/ 2 *$ Unit inventory cost per day *30

Transport cost $=$ weight $\mathrm{x}$ distance freight rate

Logistics cost $=$ inventory cost + transportation cost + other expenses

Table 1 is the calculation. 
Table 1 Distance and demand between Guangzhou and Zhengzhou

\begin{tabular}{|l|c|c|c|}
\hline City & Distance to Guangzhou $(\mathrm{km})$ & Distance to Zhengzhou $(\mathrm{km})$ & Demand (ton) \\
\hline Wuhan & 2017 & 412 & 75 \\
\hline Zhengzhou & 1605 & 0 & 100 \\
\hline Shijiazhuang & 2176 & 511 & 50 \\
\hline Hefei & 2155 & 577 & 50 \\
\hline Xi'an & 1022 & 514 & 150 \\
\hline Taiyuan & 1391 & 602 & 75 \\
\hline Total & 10366 & 2616 & 500 \\
\hline
\end{tabular}

3.3.2 Calculation comparison

(1) Enterprise self-distribution

Inventory cost $==\frac{100000}{2} \times 0.2 \times 0.02 \times 30=6000$

Transport costs are shown in Table 2 .

Table 2 Self-distribution Freight

\begin{tabular}{|l|l|l|l|l|l|l|l|}
\hline City & Wu han & Zheng zhou & Shijiazhuang & He fei & Xi'an & Tai yuan & Total \\
\hline $\begin{array}{l}\text { Cost } \\
\text { (RMB) }\end{array}$ & 61320 & 64200 & 60510 & 41730 & 63520 & 43100 & $\begin{array}{l}31438 \\
0\end{array}$ \\
\hline
\end{tabular}

Transportation costs of enterprises $=314380$

(2) Integration mode of warehouse allocation

Total logistics cost $=314380+6000+10000=330380$

The total cost of transportation is $10366 \mathrm{~km}$.

Inventory cost $=100000 / 2 \times 0.2 \times 0.03 \times 30=9000$

Transport costs are shown in Table 3.

Table 3 Freight

\begin{tabular}{|l|l|l|l|l|l|l|l|}
\hline City & Wu han & Zheng zhou & Shijiazhuang & He fei & Xi'an & Tai yuan & Total \\
\hline Cost (RMB) & 23130 & 240750 & 9270 & 13545 & 7655 & 8655 & $\begin{array}{l}30300 \\
5\end{array}$ \\
\hline
\end{tabular}

Transportation costs $=303005$

The total logistics cost is $=9000+303005+1000 \mathrm{x}$ 6=318005 RMB

In the warehouse distribution center for transportation, the time it takes to consider only the warehouse distribution center to the other 5 city distance, without considering the enterprise's journey from Guangzhou to Zhengzhou, because the process can be completed before delivery in transportation. The total delivery distance is $2616 \mathrm{~km}$.

(3) Comparative analysis

First, compare the inventory cost of the product. Because of $6000<9000$, the storage cost of the enterprise is lower than that of the storage center. This is due to the establishment of warehouse center warehouse will be selected more developed areas, and the enterprise self-built warehouse is generally based on low cost as the goal.

Then, compare transportation costs. Because of $303005<314380$, the transportation cost of enterprise self-distribution is higher than that of warehouse allocation. This has two effects, one is the warehouse distribution center location will make the whole transportation distance is shortened, two is due to warehouse distribution center professional services, large-scale transportation will make the transport rate lower than their own.

Secondly, the transportation time is compared. Because of $2616<10366$, the enterprise self-distribution time is much longer than the warehouse integration. This is because the location of the warehouse allocation center is more reasonable and more reasonable than the location of the enterprise itself, so the overall transportation route is greatly reduced.

Finally, the total logistics cost is compared. Because of $318005<330380$, the logistics cost of enterprise self-distribution is higher than that of warehouse allocation. Although the cost of warehousing is low, but the transportation distance is longer, the scope is wider, the proportion of transportation cost is much more than the inventory cost, so the transportation cost determines the size of the logistics cost.

\subsection{Analysis of influencing factors}

There are several main research indexes that can be extracted, such as sales volume, freight rate, warehousing cost and distance.

(1) Sales volume. Now suppose that the sales volume of $\mathrm{S}$ tons is uncertain, we should discuss the corresponding logistics cost under the two modes, and then use the equilibrium point analysis method to find out the critical sales volume.

Warehousing costs of self-distribution enterprises: $40 \mathrm{~S} \times 0.02 \times 30=24 \mathrm{~S}$; Warehousing costs of self-distribution enterprises: $40 \mathrm{~S} \times 0.03 \times 30=36 \mathrm{~S}$; Logistics cost of enterprise self-distribution: C1=652.76S+6000; Logistics cost of integrated distribution of warehouse and distribution: C2=642.03S+10000; Simultaneous equations are obtained: $652.76 \mathrm{~S}+6000=642.03 \mathrm{~S}+10000, \mathrm{~S}=373$; That 
is, the monthly sales of enterprises more than 373 tons (74600 pieces), we should choose the warehouse distribution model. By the formula, the bigger the scale enterprises should choose positions with integration, while reducing the cost will be more obvious.

(2) Storage level. Business enterprise in the storage level of more developed area selection of distribution center, because the enterprise must consider the protection and maintenance of products in storage, warehouse and distribution center according to different product characteristics improve storage link adaptation, and low storage cost is more conducive to the enterprises in the long-term inventory. These requirements can only be satisfied when the local storage level is high; otherwise, some enterprises with strict warehousing requirements will abandon warehouse integration because of warehousing factors.

(3) Distribution level. The distribution level of the warehouse allocation center is higher than the local level of the enterprise. With the above calculation process, it can be seen that under the same route, the lower the freight, the lower the cost. Therefore, the lower the cost of warehouse integration, the more inclined to choose the mode of electricity supplier enterprises.

(4) Journey. The pace of distribution depends mainly on the degree of customer dispersion. The more dispersed customers, the more enterprises tend to choose warehouse integration model; the more concentrated customers, enterprises will prefer to choose self-distribution.

In addition to the above analysis of the cost and time, the logistics service level of the two modes is also very different. Enterprises in the mode of self distribution, under normal circumstances, in dealing with orders, logistics facilities, equipment specialization is not high, the staff is not professional enough. This leads to the goods in sorting, handling, loading and unloading, stowage has no advantages, and will spend a lot of time in these areas, which makes the overall quality of logistics services is not high. The warehouse center will be equipped with professional staff and standardized, automated logistics equipment. This is a very significant role for improving the efficiency of logistics. At the same time, warehouse center will arrange suitable warehouse types for different goods, such as cold chain warehouse, automated warehouse, and so on, to provide high quality logistics services.

\section{CASE STUDY OF WAREHOUSE ALLOCATION INTEGRATION UNDER B2C BACKGROUND}

\subsection{Case introduction}

Electricity supplier enterprise A is located in Guangzhou City, the courier enterprises transport fees headed by $12 \mathrm{RMB} / \mathrm{KG}$, continued heavy $5 \mathrm{RMB} / \mathrm{KG}$, warehouse center price led by $8 \mathrm{RMB} / \mathrm{KG}$, continued heavy $2 \mathrm{RMB} / \mathrm{KG}$. If the enterprise stores itself, the simplified storage cost is $0.3 \mathrm{RMB} /$ piece per day, and the other cost is $3000 \mathrm{RMB}$. If there is a common warehouse for electronic goods, the inventory cost is 0.4 $\mathrm{RMB} /$ piece per day, and the other cost is $5000 \mathrm{RMB}$.
The number of days per month is 30 days. There are 5000 products in the enterprise at the beginning of the month every month, at the end of 0 . Customer demand is continuous and uniform, enterprises purchase in the first month, to the end of the stock is 0. And the replenishment time is ignored. The average weight of each item is $0.5 \mathrm{~kg}$, and the average monthly order quantity is 3000 . The average monthly order is 1500 orders greater than $1 \mathrm{~kg}$, and the total weight is more than $500 \mathrm{~kg}$.

\subsection{Calculation}

(1) Enterprise self-distribution:

Assume that 10 orders are not more than $1 \mathrm{~kg}$, then the total freight is: $10 \times 12=120$; if the weight of $\mathrm{X}$ exceeds $1 \mathrm{~kg}$, and exceeds $\mathrm{t} \mathrm{kg}$, the total freight is $10 *$ $12+\mathrm{t} * 5=120+5 \mathrm{t}$. The response time of an enterprise to an order is 4 hours. Storage costs of enterprises: $(5000 / 2) * 30 * 0.3=13500$. The total distribution and transportation cost of enterprises: $3000 \times 12+500 \times 5=38500$; the logistics cost of the enterprise is: $38500+13500+3000=55000$.

(2) Integration of warehouse and distribution:

Assume that 10 orders are not more than $1 \mathrm{~kg}$, and then the total freight is: $10 \times 8=80$; if the $\mathrm{X}$ weight exceeds $1 \mathrm{~kg}$ in the order and exceeds $\mathrm{t} \mathrm{kg}$ in total, the total freight is: $10 \times 8+t \times 2=80+2 t$. The response time of an enterprise to an order is 0 hours.

Storage costs of enterprises: $(5000 / 2) * 30 * 0.4=18000$; The total distribution and transportation cost of enterprises: $3000 \times 8+500 \times 2=25000$; The logistics cost of the enterprise is: $25000+18000+5000=48000$.

\subsection{Comparative analysis}

Because $(80+2 t)<(120+5 t)$, if only consider the distribution cost, the enterprise adopts the warehouse integration distribution mode. Because of $0.5>0.3$, enterprises only consider inventory costs, enterprises choose to store in their own warehouse. Due to the $48000<55000$, when the enterprise considers the total logistics cost, the selection of integrated distribution mode will reduce the total cost of the enterprise. Because of the $4>0$, the quality of service and the reaction time of the self-distribution are not good when the warehouse integration mode is adopted.

In conclusion, the inventory cost is relatively low, but the distribution cost is higher, the reaction time is long, the logistics service quality is poor, and the total logistics cost is relatively high. But when the enterprise uses the warehouse integration model, although the inventory cost is higher, but the distribution cost and the service quality all have the superiority, the total logistics cost is low. Therefore, e-commerce enterprises choose warehouse integration model, not only can reduce costs, but also improve the quality of service.

\subsection{Analysis of influencing factors}

In the B2C mode, the main factors that affect the choice of e-commerce enterprises are warehouse delivery time, logistics costs, customer satisfaction and other. The main indicators are: order quantity, storage fee, delivery fee and time. When the above indexes are discussed, only one variable is considered, and other variables are 
fixed.

Suppose that the electricity supplier has $\mathrm{X}$ orders per month, and the default is no more than $1 \mathrm{~kg}$.

The logistics cost of the enterprise is $\mathrm{C} 1=12 \mathrm{X}+4.5 \mathrm{X}+3000$

The logistics cost of warehouse integration is $\mathrm{C} 2=8 \mathrm{X}+6 \mathrm{X}+5000$

Using equilibrium point analysis, we get $X=800$, that is, when the order quantity is not less than 800 pieces, we should choose warehouse integration.

The enterprise considers the distribution mode from the storage level, the higher the warehousing cost of the warehouse allocation center, the more enterprises tend to choose their own storage. The lower the distribution cost of warehouse allocation center, the greater the possibility of enterprises to choose warehouse allocation integration. Finally, time. The higher the efficiency of warehouse allocation center and the shorter the delivery time, the more likely the enterprise to choose the integration is due to customer satisfaction.

\section{CONCLUSIONS}

Analysis of the integration of warehouse allocation of electricity providers, respectively, from the two common business models B2B and B2C start, discussed. This paper mainly discusses the integration of warehouse and warehouse from the micro aspect, analyzes the difference between enterprises taking and not taking warehouse integration, and the most obvious indicator is the cost of enterprises. Through the analysis and comparison of enterprise cost in different distribution mode size and service level, so as to get a better distribution mode. E-commerce enterprises choose warehouse integration, because the warehouse allocation center location and professional equipment is better than the enterprise self-distribution, making the overall transportation distance shorter, reduce logistics costs, improve efficiency. Moreover, the logistics specialization and scale of the warehouse allocation center are higher than the enterprise itself, which makes the distribution cost lower and the service quality better. No matter from the enterprise's own operations or from the external effect of the whole society, commercial enterprises to take positions with integration mode are very good, not only can reduce the cost of enterprise and enterprise to increase added value.

\section{ACKNOWLEDGEMENTS}

This research is supported by National Natural Science Foundation of China (Grant No. U1604150), Humanities \& Social Sciences Research Foundation of Ministry of Education of China (Grant No.15YJC630148), Distinguished Young Teacher Development Foundation of Zhengzhou University (1421326092), and Key Research Foundation of University Education in Henan province (17A520058). The authors would like to thank the editors and anonymous referees for their careful and fruitful comments to improve the quality of this paper.

\section{REFERENCES}

[1] Jin Cai, 2004. Statistics on the current situation of logistics development in China. China storage and transportation, 1, pp. 24-27.

[2] Linhai Nie, 2014. The characteristics and trends of the development of China's e-commerce logistics. Journal, 6, pp.97-101.

[3] Zhiwei Cao, 2015. Study on e-commerce logistics distribution model. China market, 37, pp. 38-39.

[4] Jiang Lu, 2008. Analysis and Prospect of the development of China's logistics industry [J]. Finance and economics circles, 5, pp. 97-99.

[5] Ting $\mathrm{Xu}, 2014$. Study on logistics distribution mode and development strategy of B2C e-commerce enterprises in China. Jiangsu Shang theory, 3, pp. 58-60.

[6] Qian Zhang, 2013. Research on business model of third party logistics enterprises under e-commerce environment. China Electronic Commerce, 13, pp.15-16.

[7] Hong Zhao, 2014. B2C e-commerce enterprise logistics network analysis and optimization. logistics technology, 8, pp. 48-51.

[8] Jun Yan, 2015. Hui Liu. Research on the development status and optimization strategy of express delivery industry in China. Logistics technology: equipment edition, 34 (6), pp.64-66.

[9] Rong Jin, 2010. Research on enterprise logistics operation mode under e-commerce environment. Logistics technology, 29 (11), pp. 123-124.

[10] Bowen Sun, 2015. Discussion on the development strategy of enterprise e-commerce in China. Modern economic information, 2, pp. 112-112. 